\title{
Clinical Predictors for Response to Proton Pump Inhibitor Treatment in Patients With Globus
}

\author{
Hye Kyung Jeon, Gwang Ha Kim, ${ }^{*}$ Mun Ki Choi, Jae Hoon Cheong, Dong Hoon Baek, Gwang Jae Lee, Hang Mi Lee, Bong \\ Eun Lee and Geun Am Song
}

Department of Internal Medicine, Pusan National University School of Medicine, Busan, Korea

\begin{abstract}
Background/Aims
Globus is a persistent or intermittent non-painful sensation of a lump or foreign body in the throat. Given the benign nature of the condition and the association of gastroesophageal reflux disease, empirical therapy with proton pump inhibitor seems reasonable for patients with typical globus. The aim of this study was to investigate the clinical predictors for symptom response to short-term proton pump inhibitor treatment in patients with globus symptom.
\end{abstract}

\section{Methods}

Fifty-four patients with globus symptom were enrolled prospectively. All patients were treated with pantoprazole $40 \mathrm{mg}$ daily for 4 weeks. Treatment response was defined as a $>50 \%$ reduction in symptom scores between symptom assessments. Univariate and multivariate logistic regression analysis between responders and non-responders was performed to identify variables predicting response to pantoprazole treatment.

\section{Results}

Of the 54 consecutive patients considered, 13 were excluded on the basis of exclusion criteria and/or refusal to participate in the study. Finally, 41 patients were included in this study. After 4-week pantoprazole treatment, 22 patients (53.7\%) were classified as responders. On multivariate analysis, the presence of reflux symptom was associated with a higher response rate to 4-week pantoprazole treatment $(O R, 68.56 ; P=0.043)$, and long symptom duration ( $\geq 3$ months) were associated with a lower response rate to pantoprazole treatment $(O R, 0.03 ; P=0.034)$.

\section{Conclusions}

Presence of reflux symptom and short symptom duration were independent predictors of responsiveness to 4-week pantoprazole treatment in patients with globus.

(J Neurogastroenterol Motil 2013;19:47-53)

\section{Key Words}

Clinical predictor; Gastroesophageal reflux; Globus; Proton pump inhibitors

Received: October 12, 2012 Revised: November 12, 2012 Accepted: December 12, 2012

(c) This is an Open Access article distributed under the terms of the Creative Commons Attribution Non-Commercial License (http://creativecommons. org/licenses/by-nc/3.0) which permits unrestricted non-commercial use, distribution, and reproduction in any medium, provided the original work is properly cited.

*Correspondence: Gwang Ha Kim, MD

Department of Internal Medicine, Pusan National University School of Medicine and Biomedical Research Institute, Pusan National University Hospital, 179, Gudeok-ro, Seo-gu, Busan 602-739, Korea Tel: +82-51-240-7869, Fax: +82-51-244-8180, E-mail: doc0224@pusan.ac.kr

Financial support: This study was supported by a Pusan National University Research Grant for 2 years.

Conflicts of interest: None.

Author contributions: Gwang Ha Kim and Geun Am Song designed the research. Gwang Ha Kim, Mun Ki Choi, Jae Hoon Cheong, Dong Hoon Baek, Gwang Jae Lee, Hang Mi Lee and Bong Eun Lee performed the research. Hye Kyung Jeon and Gwang Ha Kim analyzed the data. Hye Kyung Jeon and Gwang Ha Kim wrote the paper. 


\section{Introduction}

Globus is a persistent or intermittent non-painful feeling of something stuck or a sensation of a lump in the throat. It is a common condition that accounts for around $4 \%$ of otolaryngological referrals, ${ }^{1}$ and usually long-lasting, difficult to treat, and has a tendency to recur. Furthermore, due to the uncertain etiology of globus, it remains difficult to establish standard investigation and treatment strategies for affected patients. The etiology of globus is still unknown but appears to be multifactorial. Some studies have suggested that gastroesophageal reflux disease (GERD) is a major cause of globus. ${ }^{2-6}$ Therefore, it seems practical that anti-reflux treatment should be the first attempted method for managing patients with globus. ${ }^{7}$ Proton pump inhibitors (PPIs) play an important role in medical treatment of GERD, and prescriptions for PPIs have increased over tenfold since 1990., According to a British survey of otolaryngologists, the most common symptom (apart from classic heartburn) for which PPIs were prescribed was globus. ${ }^{10}$

However, the meta-analysis failed to demonstrate superiority of PPIs over placebo in patients with laryngopharyngeal reflux (LPR) including globus. ${ }^{11}$ In contrast, a recent non placebo-controlled study showed PPI efficacy of improving LPR (including globus) symptoms and signs using large scaled patients. ${ }^{12}$ In addition, few data on clinical predictors of symptom response to PPIs in patients with globus has been reported. Therefore, the aim of this study was to investigate the response rate and clinical predictors of symptom response to short-term PPI treatment in patients with globus.

\section{Materials and Methods}

\section{Patients}

In this prospective study, we enrolled 54 consecutive patients with globus symptom as a primary complaint from July 2009 to December 2010. All patients were aged $\geq 18$ years and had experienced at least 2 episodes of globus symptom per week, regardless of severity, over the last 1 month. First of all, all patients underwent otolaryngological assessment with neck/thyroid palpation and laryngoscopy, and no one had any organic abnormality on assessment. In addition, all patients underwent upper endoscopy within 2 weeks after their visit. The following exclusion criteria were applied: use of any PPI or histamine type 2 receptor antagonist during the last 2 months, presence of any severe systemic disease and/or neoplasia, use of drugs known to cause gastrointestinal motility, previous esophageal or gastric surgery, and frank peptic ulcer.

This study was carried out in accordance with good clinical practice and the Declaration of Helsinki guidelines and was approved by the Institutional Review Board at Pusan National University Hospital.

\section{Symptom Assessment}

The severity of globus was scored using a 4-point Likert scale: 0 , absent (no symptoms); 1, mild (symptoms easily tolerated and did not interfere with usual activities); 2, moderate (symptoms caused some discomfort and sometimes interfered with usual activities); and 3, severe (symptoms caused much discomfort and interfered considerably with usual activities). The frequency of symptoms was scored as days per week (frequency score: $0-7)$. Symptom scores were calculated by multiplying the severity score and the frequency score, with the maximum score equal to $21 .^{13} \mathrm{~A}$ higher score indicates more severe symptoms. Symptom duration was largely classified into 2 groups: $<3$ and $\geq 3$ months. ${ }^{14}$

The presence or absence of typical reflux symptoms (heartburn or acid regurgitation) was also assessed. GERD was considered to be present if typical symptoms occurred over 2 times per week before the pantoprazole trial.

\section{Assessment by Endoscopy}

The presence or absence of reflux esophagitis, endoscopically suspected esophageal metaplasia (ESEM), and hiatal hernia were determined, and gastroesophageal flap valve (GEFV) and atrophic gastritis were graded prospectively according to the criteria below by one endoscopist (Kim $\mathrm{GH}$ ) during endoscopic examination. In addition, the oropharynx and vocal cord were checked in all subjects before endoscope insertion into the esophagus. Gastric antral and corpus biopsy samples were taken for the detection of Helicobacter pylori infection by rapid urease test.

\section{Reflux esophagitis}

If esophagitis was present, it was graded according to the Los Angeles (LA) classification. ${ }^{15}$

\section{Endoscopically suspected esophageal metaplasia}

The presence or absence of ESEM in the lower portion of the esophagus including the esophagogastric junction was examined during inflation of the esophagus before endoscope insertion into the stomach. The esophagogastric junction was defined as 
the oral-side end of the fold that is present continuously from the gastric lumen, ${ }^{16}$ as well as the anal-side end of the fine longitudinal vessel. ${ }^{17,18}$ The squamo-columnar junction was defined by a clear change in the color of the mucosa. ESEM was defined as the area between the squamo-columnar junction and the esophagogastric junction.

\section{Hiatal hernia}

Hiatal hernia was defined as a circular extension of the gastric mucosa above the diaphragmatic hiatus greater than $2 \mathrm{~cm}$ in axial length.

\section{Gastroesophageal flap valve}

The gastroesophageal junction was viewed using a retroflexed endoscope during gastric inflation. GEFV was graded from I to IV according to Hill's grading. ${ }^{19}$ GEFV was largely classified into 2 groups: normal GEFV (grade I and II) and abnormal GEFV (grade III and IV). ${ }^{20,21}$

\section{Atrophic gastritis}

The grade of atrophic gastritis was assessed endoscopically using the atrophic pattern system described by Kimura et al. ${ }^{22,23}$ This classification divides the extent of atrophy into closed and open types. In the closed-type, the atrophic border remains on the lesser curvature of the stomach, while in the open-type, the atrophic border no longer exits on the lesser curvature but extends along the anterior and posterior walls of the stomach.

\section{Study Design}

At enrollment, all patients were treated with pantoprazole 40 $\mathrm{mg}$ daily for 4 weeks. The medication was taken once daily in the morning by all patients. The enrolled patients also attended the hospital for assessment of symptom scores after 4 weeks. Poor compliance was defined as taking less than $80 \%$ of the total medication. Treatment response was defined as a $>50 \%$ reduction in symptom scores between the 2 symptom assessments. ${ }^{24,25}$ Score improvement was calculated using the following equation:

\section{$\frac{\text { Score at treatment }- \text { Score at baseline }}{\text { Score at baseline }} \times 100$}

Body mass index (BMI), smoking, alcohol, concomitant diseases and regular aspirin use were also recorded. The BMI was categorized into the following 3 levels in accordance with the WHO guidelines for the Western Pacific region: normal-weight BMI, $<23 \mathrm{~kg} / \mathrm{m}^{2}$; overweight BMI, $\geq 23 \mathrm{~kg} / \mathrm{m}^{2}$ and $<25$ $\mathrm{kg} / \mathrm{m}^{2}$; and obese BMI, $\geq 25 \mathrm{~kg} / \mathrm{m}^{2}{ }^{26}$

\section{Statistical Methods}

Data were expressed as mean $\pm \mathrm{SD}$. Univariate analysis between responders and non-responders was performed using the Student's $t$ test for age and the $\chi^{2}$ test for non-parametric data (gender, BMI, smoking, alcohol drinking, concomitant diseases, aspirin intake, symptom duration, symptom score, $H$. pylori infection, reflux esophagitis, ESEM, hiatal hernia, GEFV and atrophic gastritis).

Multivariate logistic regression analysis was used to identify variables predicting the response to 4-week pantoprazole treatment, initially by entering all independent variables at a single step. To stay within the model, variables were required to be significant at a $5 \%$ significance level. Odds ratios (ORs) were expressed with their $95 \%$ confidence intervals (CIs). A $P$-value $<0.05$ was considered statistically significant. The statistical calculations were performed with SPSS software version 12.0 for Windows (SPSS Inc., Chicago, IL, USA).

\section{Results}

\section{Study Population}

Of the 54 consecutive patients considered, 13 were excluded on the basis of exclusion criteria and/or refusal to participate in the study, leaving 41 eligible patients (Figure). No patients was lost to follow-up or dropped out due to poor compliance before the final evaluation. The baseline characteristics of the study patients are shown in Table 1. The study population was comprised of 19 male and 22 female patients, with a mean age of 51.3 years. Five patients (12.2\%) were smokers, and 8 patients (19.5\%) had concurrent diseases such as hypertension, diabetes mellitus, or osteoporosis. Two patients (4.9\%) took aspirin daily for cardiovascular disease prevention. Thirty-four patients $(82.9 \%)$ had a globus symptom duration of $\geq 3$ months, and 15 patients (36.6\%) presented with less than 7 symptom score. H. pylori infection was present in 15 patients (36.6\%), and open-type atrophic gastritis was observed in 6 patients (14.6\%). Reflux esophagitis was documented in 18 patients (43.9\%), and almost all esophagitis cases were mild (LA-A or LA-B). Hiatal hernia and abnormal GEFV were observed in 5 patients $(12.2 \%)$ and 11 patients $(26.8 \%)$, respectively.

\section{Response to Pantoprazole Treatment}

After 4-week pantoprazole treatment, 22 of 41 (53.7\%) pa- 


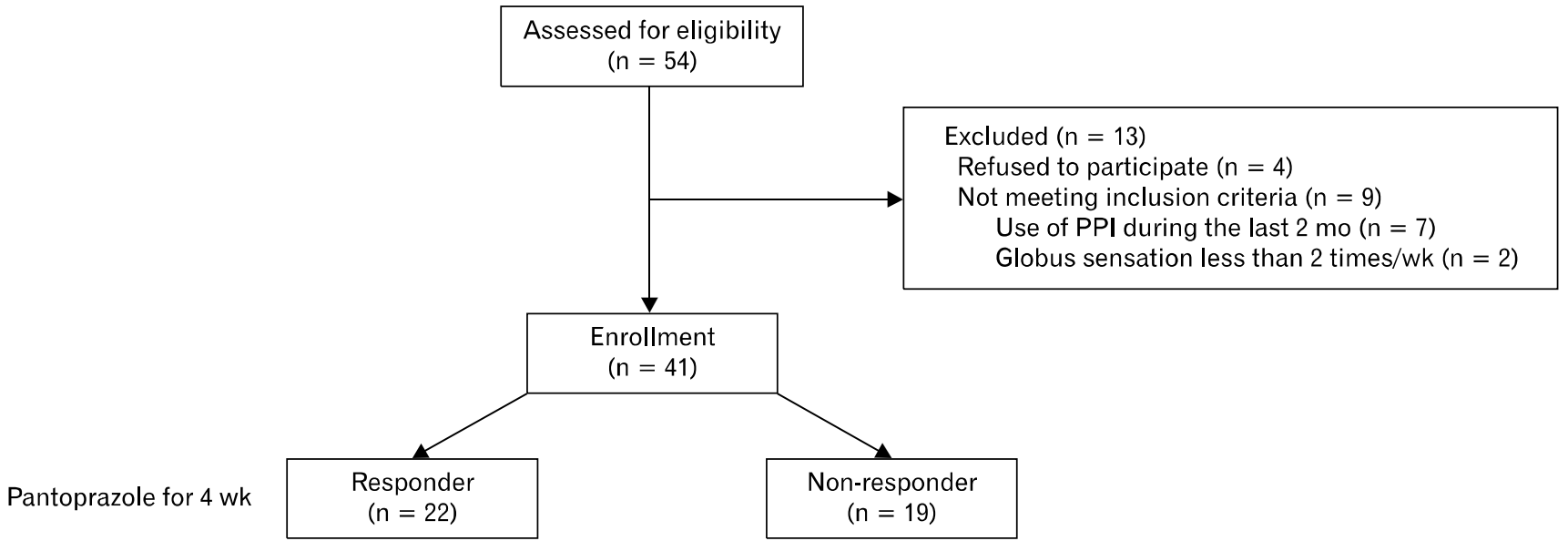

Figure. Flow chart of study patients. PPI, proton pump inhibitor.

Table 1. Baseline Demographics, and Clinical and Endoscopic Characteristics of the Study Population $(\mathrm{N}=41)$

\begin{tabular}{lc}
\hline \multicolumn{1}{c}{ Variables } \\
\hline Gender (male/female, $\mathrm{n})$ & $19 / 22$ \\
Age (mean $\pm \mathrm{SD}, \mathrm{yr})$ & $51.3 \pm 9.7$ \\
Body mass index (mean $\left.\pm \mathrm{SD}, \mathrm{kg} / \mathrm{m}^{2}\right)$ & $23.7 \pm 2.5$ \\
Smoking (n [\%]) & $5(12.2)$ \\
Alcohol drinking (n [\%]) & $17(41.5)$ \\
Associated diseases (n [\%]) & $8(19.5)$ \\
Aspirin intake (n [\%]) & $2(4.9)$ \\
Reflux symptoms ${ }^{\mathrm{a}}(\mathrm{n}[\%])$ & $22(53.6)$ \\
Symptom duration (n [\%]) & \\
$<3$ mo & $7(17.1)$ \\
$\geq 3$ mo & $34(82.9)$ \\
Symptom score (n [\%]) & \\
$<7$ & $15(36.6)$ \\
$\geq 7$ & $26(63.4)$ \\
H. pylori infection (n [\%]) & $15(36.6)$ \\
Reflux esophagitis (n [\%]) & $18(43.9)$ \\
A & $13(31.7)$ \\
B & $4(9.8)$ \\
C & $1(2.4)$ \\
D & $0(0.0)$ \\
Endoscopically suspected esophageal metaplasia (n [\%] $)$ & $1(2.4)$ \\
Hiatal hernia (n [\%]) & $5(12.2)$ \\
Gastroesophageal flap valve (n [\%]) & \\
Type I & $10(24.4)$ \\
Type II & $20(48.8)$ \\
Type III & $11(26.8)$ \\
Atrophic gastritis (n [\%]) & $0(0.0)$ \\
Closed-type & \\
Open-type & $35(85.4)$ \\
\hline & \\
\hline & \\
&
\end{tabular}

${ }^{a}$ Heartburn and acid regurgitation over twice per week.

H. pylori, Helicobacter pylori. tients were classified as responders because their total symptom score had improved by at least $50 \%$. There was no significant difference in sex, age, BMI, smoking habit and endoscopic finding between responders and non-responders. Responders had a higher frequency of presence of GERD symptoms, shorter symptom duration ( $<3$ months), and lower symptom score $(<7)$ than non-responders, but without significance in statistics (Table 2).

\section{Multivariate Analysis of Predictive Factors to Pantoprazole Treatment Response}

Multiple logistic regression analysis revealed presence of GERD symptoms and longer symptom duration to be relevant independent pre-treatment factors for prediction of 4-week treatment response (Table 3). Patients with GERD symptoms demonstrated a higher response rate to 4-week pantoprazole treatment (OR, 68.56; $P=0.043)$. Patients with longer symptom duration showed a lower response rate to 4-week treatment (OR, $0.03 ; P=0.034)$.

\section{Discussion}

Most investigators have suggested that patients with LPR, where globus is a common symptom, require more aggressive and more prolonged therapy than those with typical GERD. ${ }^{27}$ Empirical twice-daily therapy with PPIs for at least 3 months is usually recommended. ${ }^{7}$ However, duration of 7-14 days is considered to be probably long enough to determine the effect of the PPI and enough to reach a steady-state inhibition of acid secretion. ${ }^{28,29}$ Furthermore, although optimal dose of PPI therapy is twice daily, ${ }^{30}$ single dose has also plausible effect on LPR 
Table 2. Outcome of 4-week Pantoprazole Treatment: Possible Pre-treatment Influencing Factors

\begin{tabular}{|c|c|c|c|}
\hline & $\begin{array}{l}\text { Responder } \\
(\mathrm{n}=22)\end{array}$ & $\begin{array}{l}\text { Non- } \\
\text { responder } \\
(\mathrm{n}=19)\end{array}$ & $P$-value \\
\hline Male:female (n) & $11: 11$ & $8: 11$ & 0.756 \\
\hline Age (mean $\pm \mathrm{SD}, \mathrm{yr})$ & $52.0 \pm 9.9$ & $50.6 \pm 9.7$ & 0.647 \\
\hline Body mass index (n [\%]) & & & 0.233 \\
\hline$<25 \mathrm{~kg} / \mathrm{m}^{2}$ & $15(68.2)$ & $16(84.2)$ & \\
\hline$\geq 25 \mathrm{~kg} / \mathrm{m}^{2}$ & $7(31.8)$ & $3(15.8)$ & \\
\hline Smoking (n [\%]) & $4(18.2)$ & $2(10.5)$ & 0.489 \\
\hline Alcohol drinking (n [\%]) & $9(40.9)$ & $8(42.1)$ & 0.938 \\
\hline Associated diseases (n [\%]) & $3(13.6)$ & $5(26.3)$ & 0.307 \\
\hline Aspirin intake (n [\%]) & $1(4.5)$ & $1(5.3)$ & 0.915 \\
\hline Reflux symptoms (n [\%]) & & & 0.166 \\
\hline Present & $19(86.4)$ & $13(68.4)$ & \\
\hline Absent & $3(13.6)$ & $6(31.6)$ & \\
\hline Symptom duration (n [\%]) & & & 0.062 \\
\hline$<3$ months & $6(27.3)$ & $1(5.3)$ & \\
\hline$\geq 3$ months & $16(72.7)$ & $18(94.7)$ & \\
\hline Symptom score (n [\%]) & & & 0.055 \\
\hline$<7$ & $11(50.0)$ & $4(21.1)$ & \\
\hline$\geq 7$ & $11(50.0)$ & $15(78.9)$ & \\
\hline H. pylori infection (n $[\%]$ ) & & & 0.536 \\
\hline Present & $9(40.9)$ & $6(31.6)$ & \\
\hline Absent & $13(59.1)$ & $13(68.4)$ & \\
\hline Reflux esophagitis (n [\%]) & & & 0.295 \\
\hline Present & $8(36.4)$ & $10(52.6)$ & \\
\hline Absent & $14(63.6)$ & $9(47.4)$ & \\
\hline $\begin{array}{l}\text { Endoscopically suspected } \\
\text { esophageal metaplasia (n [\%]) }\end{array}$ & & & 1.000 \\
\hline Present & $0(0.0)$ & $1(5.2)$ & \\
\hline Absent & $22(100.0)$ & $18(94.7)$ & \\
\hline Hiatal hernia (n [\%]) & & & 0.762 \\
\hline Present & $3(13.6)$ & $2(10.5)$ & \\
\hline Absent & $19(86.4)$ & $17(89.5)$ & \\
\hline Gastroesophageal flap valve (n [\%]) & & & 0.945 \\
\hline Type I, II & $16(72.7)$ & $14(73.7)$ & \\
\hline Type III, IV & $6(27.3)$ & $5(26.3)$ & \\
\hline Atrophic gastritis & & & 0.280 \\
\hline Closed-type & $20(90.9)$ & $15(78.9)$ & \\
\hline Open-type & $2(9.1)$ & $4(21.1)$ & \\
\hline
\end{tabular}

H. pylori, Helicobacter pylori.

symptoms. ${ }^{31}$ On the basis of these results, we evaluated the response to 4-week standard dose pantoprazole in patients with globus. In this study, the response rate was more than half, which is slightly higher than that $(37.5 \%)$ of the previous study in patients with globus after 2 -week high dose rabeprazole trial. ${ }^{32}$

In addition, we tried to find the pre-treatment clinical predictors to PPI and so we identified the presence/absence of reflux
Table 3. Factors Predictive of Pantoprazole Treatment Response: Multivariate Logistic Regression Analysis

\begin{tabular}{lccc}
\hline \multirow{2}{*}{ Factors } & \multicolumn{3}{c}{ After 4 weeks } \\
\cline { 2 - 4 } & $\mathrm{B}$ & OR $(95 \% \mathrm{CI})$ & $P$-value \\
\hline Reflux symptoms & 4.228 & 68.56 & 0.043 \\
Symptom duration $(\geq 3 \mathrm{mo})$ & -5.765 & $(1.14-4137.40)$ & 0.03 \\
& & $(0.00-0.65)$ & 0.034 \\
\hline
\end{tabular}

B, logistic regression coefficient.

symptom and the symptom duration as predictors. First, the presence of reflux symptoms was associated with a higher response rate to 4-week pantoprazole treatment. This result suggests that the co-existence of typical GERD symptoms in patients with globus means higher possibility of GERD as a cause of globus in these patients. Some studies have suggested that GERD is a major cause of globus. ${ }^{2-6}$ Tokashiki et al $^{2}$ reported that globus sensation can arise from GERD because the improvement rate of GERD was significantly higher in the group with improved globus than in the group with no improvement of globus after 8 weeks of lansoprazole trial. Therefore, the patients with globus having typical reflux symptoms will have more benefits from PPI than those without typical reflux symptoms. On the contrary, when typical reflux symptoms are absent, the response rate may be low after empirical PPI treatment.

Second, long symptom duration was associated with a lower response rate to pantoprazole treatment. This result is in consistent to the result of a previous long-term follow-up study. ${ }^{14}$ In that study, patients with short duration globus had the greatest chance of becoming asymptomatic or symptomatically improved. However, the lack of a placebo control group in our study makes it difficult to draw firm conclusions.

There are several limitations in this study. First, this study was not a placebo-controlled trial. We could not exclude the possibility that improvement in the globus sensation may be a placebo effect or a spontaneous cure. In addition, this study did not include other disturbing factors influencing therapeutic results, including lifestyle, caffeine ingestion and smoking. Second, we did not check the psychological history such as anxiety or depression. Stress and psychological factors have often been thought to cause or trigger the globus sensation and may affects therapeutic results. Third, we did not perform dual-probe ambulatory 24-hour esophageal pH monitoring for the evaluation of GER and LPR. Furthermore, the possibility of weak acid or non-acid reflux such as bile reflux was not addressed. In our study, most patients were di- 
agnosed with GERD based on symptoms alone. Fourth, in this study, we did not investigate the response to longer PPI treatment ( 3 or more months), i.e., we evaluated only the response to short-term PPI treatment. Lastly, the number of subjects was somewhat small for broad generalization.

Despite these limitations, this study is meaningful in the fact that there is a good response rate to standard dose PPI treatment which is the usually prescribed dose in clinics, and pre-treatment factors predicting a correlation with the improvement of globus symptoms exist. In a future, placebo-controlled PPI trials in patents with globus would be needed to find the predicting factors on good response to PPI.

In conclusion, about half patients with globus responded to PPI treatment. Presence of reflux symptoms and short symptom duration were independent predictors for 4-week pantoprazole treatment in patients with globus. These clinical predictors would be helpful in a real practice to find out which patient with globus would benefit from PPI treatment in clinics.

\section{References}

1. Moloy PJ, Charter R. The globus symptom. Arch Otolaryngol 1982;108:740-744.

2. Tokashiki R, Yamaguchi H, Nakamura K, Suzuki M. Globus sensation caused by gastroesophageal reflux disease. Auris Nasus Larynx 2002;29:347-351.

3. Chevalier JM, Brossard E, Monnier P. Globus sensation and gastroesophageal reflux. Eur Arch Otorhinolaryngol 2003;260:273-276.

4. Oridate N, Nishizawa N, Fukuda S. The diagnosis and management of globus: a perspective from Japan. Curr Opin Otolaryngol Head Neck Surg 2008;16:498-502.

5. Park KH, Choi SM, Kwon SU, Yoon SW, Kim SU. Diagnosis of laryngopharyngeal reflux among globus patients. Otolaryngol Head Neck Surg 2006;134:81-85.

6. Tokashiki R, Funato N, Suzuki M. Globus sensation and increased upper esophageal sphincter pressure with distal esophageal acid perfusion. Eur Arch Otorhinolaryngol 2010;267:737-741.

7. Lee BE, Kim GH. Globus pharyngeus: a review of its etiology, diagnosis and treatment. World J Gastroenterol 2012;18:2462-2471.

8. Altman KW, Stephens RM, Lyttle CS, Weiss KB. Changing impact of gastroesophageal reflux in medical and otolaryngology practice. Laryngoscope 2005;115:1145-1153.

9. Ulualp SO, Toohill RJ, Shaker R. Outcomes of acid suppressive therapy in patients with posterior laryngitis. Otolaryngol Head Neck Surg 2001;124:16-22.

10. Karkos PD, Benton J, Leong SC, et al. Trends in laryngopharyngeal reflux: a British ENT survey. Eur Arch Otorhinolaryngol 2007;264: 513-517.

11. Karkos PD, Wilson JA. Empiric treatment of laryngopharyngeal reflux with proton pump inhibitors: a systemic review. Laryngoscope
2006;116:144-148.

12. Lee YS, Choi SH, Son YI, Park YH, Kim SY, Nam SY. Prospective, observational study using rabeprazole in 455 patients with laryngopharyngeal reflux disease. Eur Arch Otorhinolaryngol 2011;268:863-869.

13. Bautista J, Fullerton H, Briseno M, Cui H, Fass R. The effect of an empirical trial of high-dose lansoprazole on symptom response of patients with non-cardiac chest pain - a randomized, double-blind, placebo-controlled, crossover trial. Aliment Pharmacol Ther 2004;19: 1123-1130.

14. Timon C, O'Dwyer T, Cagney D, Walsh M. Globus pharyngeus: long-term follow-up and prognostic factors. Ann Otol Rhinol Laryngol 1991;100(5 Pt 1):351-354.

15. Robinson M. Review article: $\mathrm{pH}$, healing and symptom relief with rabeprazole treatment in acid-related disorders. Aliment Pharmacol Ther 2004;20(suppl 6):30-37.

16. Nandurkar S, Talley NJ. Barrett's esophagus: the long and the short of it. Am J Gastroenterol 1999;94:30-40.

17. Vianna A, Hayes PC, Moscoso G, et al. Normal venous circulation of the gastroesophageal junction. A route to understanding varices. Gastroenterology 1987;93:876-889.

18. Noda T. Angioarchitectural study of esophageal varices. With special reference to variceal rupture. Virchows Arch A Pathol Anat Histopathol 1984;404:381-392.

19. Hill LD, Kozarek RA, Kraemer SJ, et al. The gastroesophageal flap valve: in vitro and in vivo observations. Gastrointest Endosc 1996;44: 541-547.

20. Hill LD, Kozarek RA. The gastroesophageal flap valve. J Clin Gastroenterol 1999;28:194-197.

21. Kim GH, Song GA, Kim TO, et al. Endoscopic grading of gastroesophageal flap valve and atrophic gastritis is helpful to predict gastroesophageal reflux. J Gastroenterol Hepatol 2008;23:208-214.

22. Kimura K, Takemoto T. An endoscopic recognition of the atrophic border and its significance in chronic gastritis. Endoscopy 1969;3: 87-97.

23. Kimura K, Satoh K, Ido K, Taniguchi Y, Takimoto T, Takemoto T. Gastritis in the Japanese stomach. Scand J Gastroenterol 1996; 31(suppl 214):17-20; discussion 21-23.

24. Fass R, Fennerty MB, Ofman JJ, et al. The clinical and economic value of a short course of omeprazole in patients with noncardiac chest pain. Gastroenterology 1998;115:42-49.

25. Cheong JH, Kim GH, Lee BE, et al. Endoscopic grading of gastroesophageal flap valve helps predict proton pump inhibitor response in patients with gastroesophageal reflux disease. Scand J Gastroenterol 2011;46:789-796.

26. WHO/IASO/IOTF. The Asian-Pacific perspective: redefining obesity and its treatment. Geneva: WHO Western Pacific Region 2000.

27. Remacle M. The diagnosis and management of globus: a perspective from Belgium. Curr Opin Otolaryngol Head Neck Surg 2008;16: 511-515.

28. Bruley des Varannes S. The proton-pump inhibitor test: pros and cons. Eur J Gastroenterol Hepatol 2004;16:847-852.

29. Bruley des Varannes S, Levy P, Lartigue S, Dellatolas F, Lemaire M, Galmiche JP. Comparison of lansoprazole with omeprazole on 24-hour intragastric $\mathrm{pH}$, acid secretion and serum gastrin in healthy volunteers. Aliment Pharmacol Ther 1994;8:309-314. 
30. Park W, Hicks DM, Khandwala F, et al. Laryngopharyngeal reflux: prospective cohort study evaluating optimal dose of proton-pump inhibitor therapy and pretherapy predictors of response. Laryngoscope 2005;115:1230-1238.

31. Reichel O, Dressel H, Wiederänders K, Issing WJ. Double-blind, placebo-controlled trial with esomeprazole for symptoms and signs associated with laryngopharyngeal reflux. Otolaryngol Head Neck Surg 2008;139:414-420

32. Sinn DH, Kim JH, Kim S, et al. Response rate and predictors of response in a short-term empirical trial of high-dose rabeprazole in patients with globus. Aliment Pharmacol Ther 2008;27:1275-1281. 